\title{
The Influences of the Nozzle Throat Length and the Orifice Grooving Degree on Internal Flow Field for a Multi-Entry Fan Nozzle Based on FLUENT
}

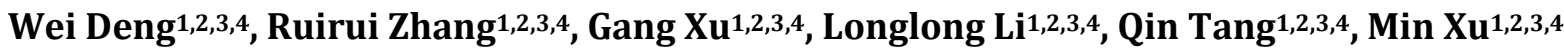 \\ ${ }^{1}$ Beijing Research Center of Intelligent Equipment for Agriculture, Beijing, China \\ ${ }^{2}$ National Research Center of Intelligent Equipment for Agriculture, Beijing, China \\ ${ }^{3}$ Key Laboratory of Agri-Informatics, Ministry of Agriculture, Beijing, China \\ ${ }^{4}$ Beijing Key Laboratory of Intelligent Equipment Technology for Agriculture, Beijing, China \\ Email: dengw@nercita.org.cn
}

How to cite this paper: Deng, W., Zhang, R.R., Xu, G., Li, L.L., Tang, Q. and Xu, M. (2019) The Influences of the Nozzle Throat Length and the Orifice Grooving Degree on Internal Flow Field for a Multi-Entry Fan Nozzle Based on FLUENT. Engineering, 11, 777-790.

https://doi.org/10.4236/eng.2019.1111052

Received: September 3, 2019

Accepted: November 19, 2019

Published: November 22, 2019

Copyright $\odot 2019$ by author(s) and Scientific Research Publishing Inc. This work is licensed under the Creative Commons Attribution International License (CC BY 4.0).

http://creativecommons.org/licenses/by/4.0/

(c) (i) Open Access

\begin{abstract}
Spray nozzle is a key component in equipment for plant protection and water-saving irrigation. The fan nozzle is a kind of spray nozzle, which is widely used in agriculture and forestry for irrigation and control of diseases, insects, and weeds. In consideration of the increasing velocity of the flow field, when the hydraulic pressure remains unchanged and the flow path becomes narrow, and because the increase of the velocity of spray drops can increase the penetrability of spray drops into the plant canopy, a kind of new fan nozzle with multi entries and simple inner structure was designed and the influences of its structure parameters on the inner flow field were analyzed using FLUENT software. The experimental results showed that the influence of the throat length on the inner flow field of the nozzle was insignificant, while the orifice grooving degree had a significant effect on inner flow field of the nozzle. The larger the grooving degree was, the smaller the pressure and velocity of internal flow field of the nozzle. The nozzle throat length had little influence on the velocity change of internal flow field. Positive correlation was shown between throat length and flow field velocity.
\end{abstract}

\section{Keywords}

Fan Nozzle, Orifice, Spray, FLUENT, Multi-Entry, Inner Flow Field

\section{Introduction}

China is an agricultural country. It is indispensable to strengthen the plant pro- 
tection work during the process of developing China's agricultural economy, because it is one of the important means to ensure high yield and stable yield of crops [1] [2] [3]. Currently, chemical control is the most effective prevention and treatment method among the three crop protection methods (physical control, chemical control, integrated control), and spraying agro-chemical pesticides is the most commonly used method in chemical control [4] [5] [6]. Especially in the face of a sudden outbreak of large-scale diseases, insects, and weed damage, spraying chemical pesticides is particularly effective [7] [8] [9]. Although the spray nozzle is only a small part of the spraying machine, its function cannot be ignored. The nozzle directly affects the spray quality. Only the nozzle with good performance can produce desired spray characteristics, such as the spray flow-rate, spray droplet size, droplet velocity, the uniformity of droplet deposition, and so on, further to improve the penetrability of the spray droplet and minimize the droplet drift and chemical loss [10] [11] [12], which is directly related to the key indicators of atomization quality [13] [14] [15] [16]. Optimizing the internal structure of plant-protection nozzles is one of the most important researches at home and abroad.

Deng Wei et al. [17] conducted relevant experimental research on the influence of different flow-rate control methods on the droplet movement velocity and droplet deposition rate of large nozzles. The research showed that suitable smaller droplet diameter spectra can be obtained and spray droplet velocity can be increased through adjusting spray duty cycle, spray pressure, and nozzle size using the method of PWM-based intermittent spray from enlarged nozzles operated at increased liquid pressure. So that, spray deposition rate could be improved. Xie Chen [18] compared the atomization process of two kinds of fan nozzles manufactured by foreign countries, which provided a reference for the development of new nozzles. Garcera C et al. [19] did a relevant comparative study on the spray droplet deposition of standard cone nozzles and venturi anti-drift nozzles. Bozdogan and the co-authors [20] studied the coverage of the pesticide liquid, the droplet drift, and the liquid residue for pesticide application in strawberry field using three different nozzles: hollow cone nozzle (MI), air-assisted rotating nozzle (M2), and flat fan nozzle (M3). Raquel et al. [21] conducted experimental research on the parameters of the spray performance for the fan-shaped mist nozzle, in terms of the radial droplet distribution and the droplet size. Miller P C H and his co-researchers [22] did experiments on flat fan nozzles and the study results showed that there were many factors affecting the spray process, which had certain influence and guidance on the nozzle design. Burguete et al. [23] studied the spray droplet size and droplet trajectory of the fan-shaped mist nozzle.

From the literatures, it is considered that the situation of few types of nozzles for agro-chemical spray application in China is one of the major gaps between China and developed countries in the field of plant protection nozzles [24] [25] [26]. Therefore, it is especially important to strengthen the nozzle design and optimization of the inner structure of nozzles for promoting the development of 
agricultural plant protection in China.

For fan nozzles, which are widely used for plant protection in China, the atomization process is that the chemical liquid enters the nozzle under the action of pressure, flowing through the nozzle throat. Due to being squeezed by the wedge surface of the slotted groove of the nozzle orifice, the squeezed liquid spreads into a planar liquid film and then differentiates into pretty small droplets. Finally, these atomized small droplets were uniformly sprayed onto the target vegetation [27] [28] [29] [30]. The main structural parameters of the fan nozzle mainly include the cutting angle of the groove on orifice, the cavity diameter, the length of the nozzle throat, and the relative cutting depth.

Design of spray nozzles involves simulation and test verification of flow field inside the spray nozzles. In recent studies, there have been some similar research methods in different fields. In reference [31], for poor spraying uniformity and short range in low-pressure sprinklers, various special-shaped nozzles were designed based on the principle of identical cross-sectional area. ANASY CFX was applied to simulate three-dimensional internal flow field in these sprinklers. The numerical simulation results were validated by using the measured performance parameters of low-pressure sprinklers, including range, water distribution and drop diameter. In literature [32], commercial software FLUENT was applied to calculate the flow pressure characteristics and internal velocity distribution of full jet nozzle under working conditions. Compared with the experimental results, the simulation results showed that the internal flow field of the full jet nozzle was in good agreement with the experimental results. According to the numerical simulation, the velocity vector diagram of the internal flow field of the full jet nozzle was obtained under direct and wall-attached conditions. Similarly, many studies showed that numerical simulation using FLUENT software can be applied effectively to analyze the flow field features inner the nozzles [26] [33] [34].

In this paper, based on the atomization principle of the nozzle, the entrance part of a fan nozzle was re-designed to be a multi-inlet, single-outlet step-like new structure. And the re-designed nozzle was simulated, focusing on two factors: the cutting angle of the orifice groove and the length of the nozzle throat.

\section{Materials and Methods}

\subsection{Design of New-Type Multi-Entry Fan Nozzle}

Based on the ordinary fan nozzle, a change of the nozzle entrance was made for trying to improve the spray characteristics. A kind of multi-inlet and single-outlet nozzle was preliminarily designed, namely, a 5-hole inlet, of which the diameter of each hole was $1 \mathrm{~mm}$ and the outlet was a V-shaped groove. The 3-D model of the modified nozzle was drawn using the 3-D drawing software "Solidworks". For the modified fan nozzle, the 3-D model diagram (a) drawn in "Solidworks", the overall external view (b), overall internal structure (c), the top view (d), the bottom view (e), the cross-sectional view (f), and the right-side view are separately showed in Figure 1. 


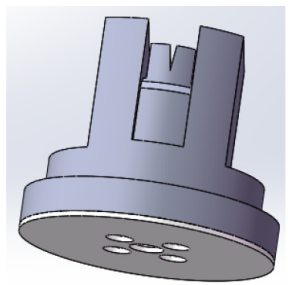

(a)

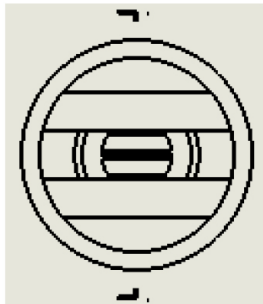

(d)

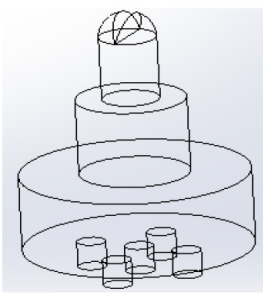

(b)

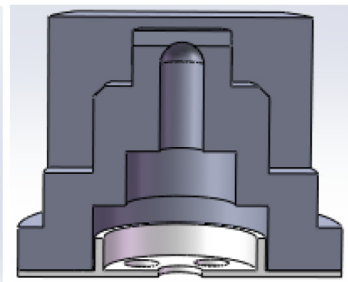

(c)

Figure 1. Views from different angles of the modified fan nozzle. (a) 3-D model; (b) overall external view; (c) overall internal structure; (d) top view; (e) bottom view; ( $\mathrm{f}$ ) cross-sectional view; (g) right-side view.

\subsection{Simulation of the Internal Flow Field of the 5-Hole-Inlet Nozzle}

\subsubsection{Meshing}

It is assumed that the fluid inside the nozzle is steady-state and incompressible, then a solid-liquid non-slip boundary is adopted. The model of the modified nozzle was imported into ANSYS for meshing. Set the five small-end faces at the bottom of the grid to be the entrance of the flow field. The two faces of the $\mathrm{V}$-shaped groove orifice was the exit of the flow field. The mesh plot is shown in Figure 2 .

\subsubsection{Numerical Simulation}

In the study, a pressure-based steady-state algorithm was used. The boundary conditions were selected as pressure inlet and pressure outlet. The inlet pressure was $3 \mathrm{Mpa}$ and the outlet pressure is atmospheric pressure. The medium was single-phase liquid water. The SIMPLE solution method belonging to the finite volume method was adopted to be the numerical simulation method which currently is the most widely used in flow field calculations in engineering practices. The governing equation was the standard $k-\varepsilon$ turbulence model, in which the equations of turbulent kinetic energy $k$ and turbulent dissipation rate $\varepsilon$ are as follows [35] [36] [37] [38]:

$$
\begin{gathered}
\frac{\partial}{\partial t}(\rho k)+\frac{\partial}{\partial x_{i}}\left(\rho k u_{i}\right)=\frac{\partial}{\partial x_{j}}\left[\left(\mu+\frac{\mu_{t}}{\sigma_{k}}\right) \frac{\partial k}{\partial x_{j}}\right]+G_{k}+G_{b}-\rho \varepsilon-Y_{M}+S_{k} \\
\frac{\partial}{\partial t}(\rho \varepsilon)+\frac{\partial}{\partial x_{i}}\left(\rho k u_{i}\right)=\frac{\partial}{\partial x_{j}}\left[\left(\mu+\frac{\mu_{t}}{\sigma_{\varepsilon}}\right) \frac{\partial \varepsilon}{\partial x_{j}}\right]+C_{1 \varepsilon} \frac{\varepsilon}{k}\left(G_{k}+G_{3 \varepsilon} G_{b}\right)-C_{2 \varepsilon} \rho \frac{\varepsilon^{2}}{k}+S_{k}
\end{gathered}
$$



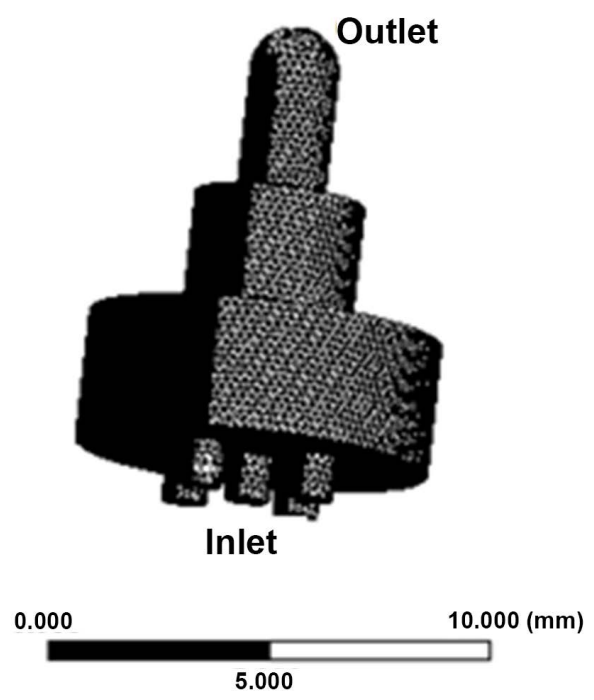

Figure 2. Meshing.

where, $\rho$ is the continuous phase density, $\mathrm{kg} / \mathrm{m}^{3} ; \varepsilon$ is the turbulent dissipation rate, $\mathrm{m}^{2} / \mathrm{s}^{3} ; k$ is the turbulent kinetic energy, $\mathrm{m}^{2} / \mathrm{s}^{2} ; \mu$ is the dynamic viscosity, pa.s; $\sigma_{k}$ is the Prandtl number of turbulent kinetic energy; $\sigma_{s}$ is the Prandtl number of dissipation rate of turbulent kinetic energy; $G_{k}$ the turbulent kinetic energy caused by laminar velocity gradient, pa/s; $Y_{M}$ is the kinetic energy generated due to the transitional diffusion in the compressible turbulent flow, $\mathrm{pa} / \mathrm{s} ; \mathrm{C}_{1 \delta}$ $\mathrm{C}_{2 \vartheta} \mathrm{C}_{3 \varepsilon}$ is the empirical constant.

\subsection{Application Software}

ANSYS software is a kind of large-scale general finite element analysis software developed by American ANSYS Inc., which can match with many design software to realize data sharing and exchange, such as Creo, NASTRAN, Alogor, AutoCAD. FLUENT Inc., which is a commercial CFD (Computer Fluid Dynamics) software commonly used in the international market and a leader in fluid simulation, was taken over by ANSYS Inc. in 2006 to integrate FLUENT into its ANSYS software. It has rich physical models, advanced numerical calculation methods, and powerful post-processing functions. The version of the ANSYS used in the study was ANSYS 15.0.

\section{Results}

\subsection{The Simulating Result}

After setting the relevant parameters, 200 times of iteration calculation were performed on the nozzle model and the residual curve appeared converged. The plots of pressure contours and velocity contours for the nozzle inlet and outlet are respectively shown in Figure 3 and Figure 4.

It can be seen from Figure 3 and Figure 4 that the pressure on the same cross section was the same for both the inlet and the outlet, while the velocity on the 

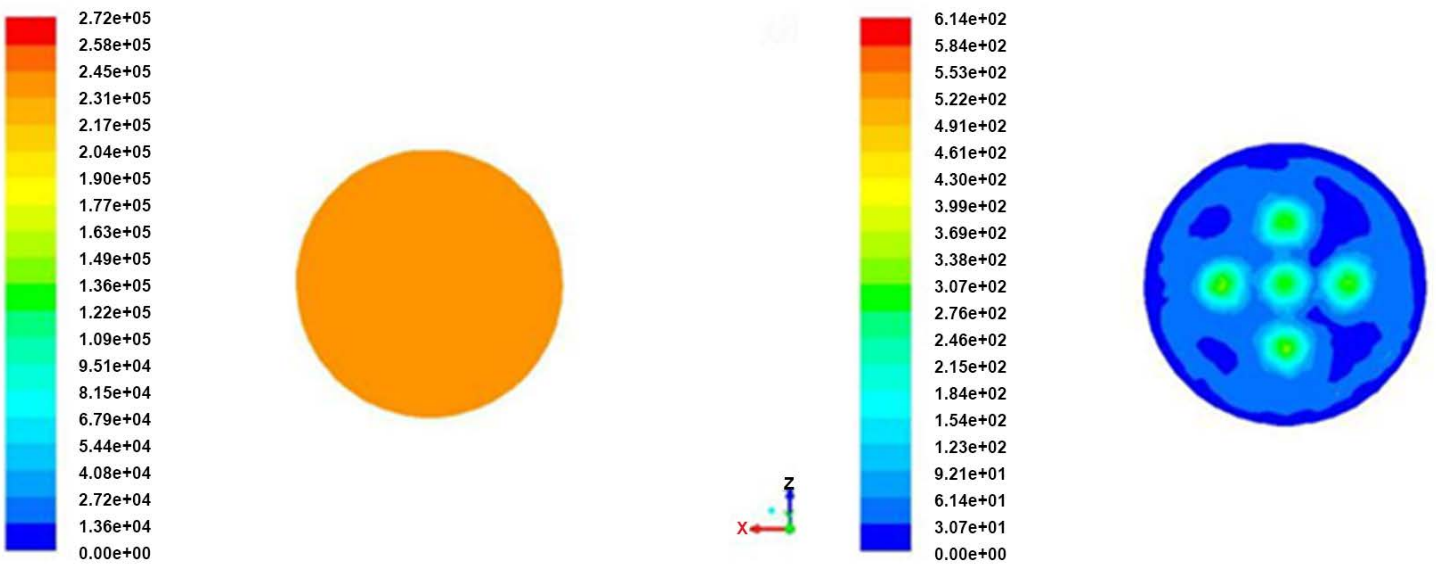

Figure 3. Plots of the pressure and velocity contour of the nozzle inlet.
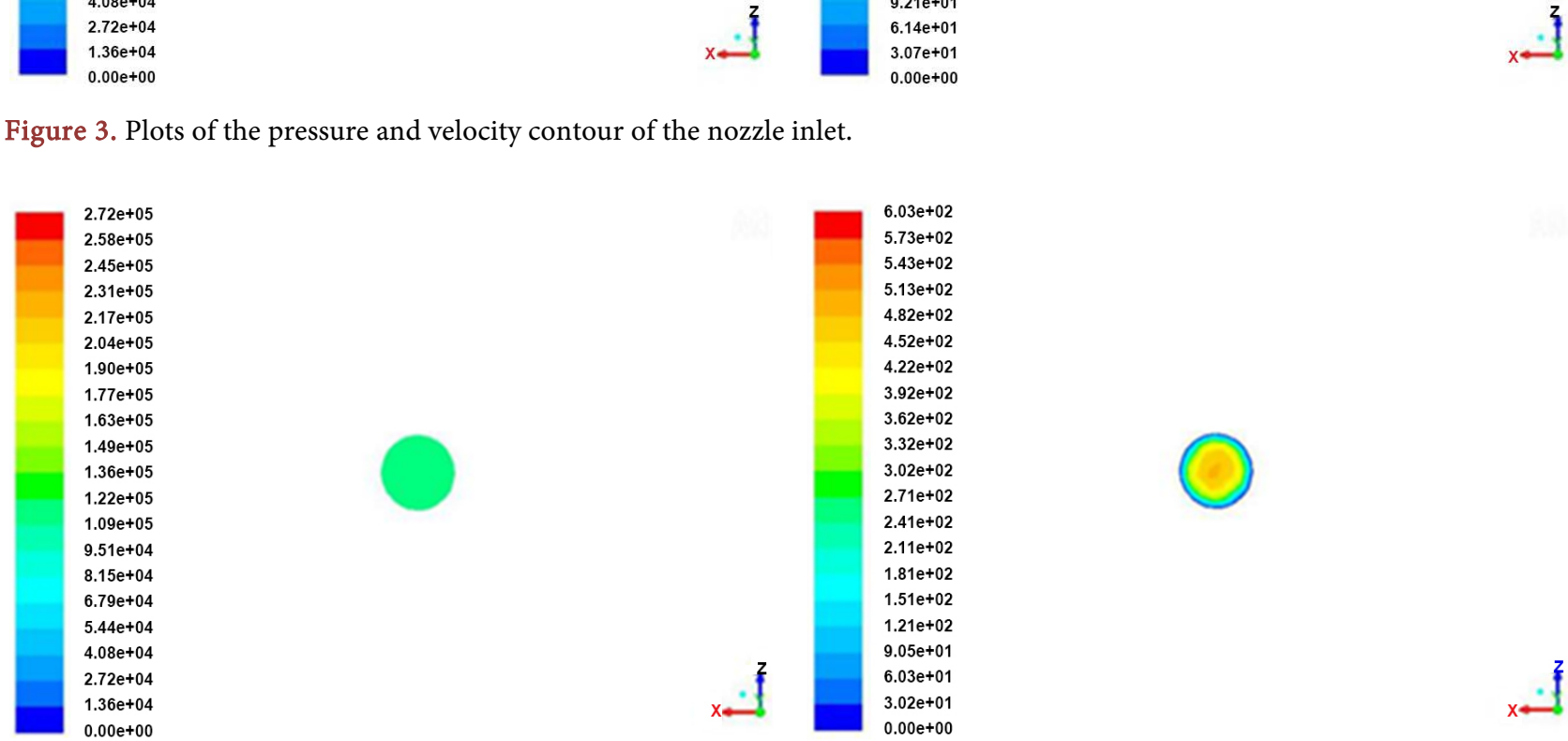

Figure 4. Plots of the pressure and velocity contour of the nozzle outlet.

same cross section was varying. The more, the pressures on same cross section of the five holes at the inlet were the same and higher than the other areas along the nozzle throat. The pressure at the outlet gradually decreased layer by layer as a rippled shape from the center to the edge.

\subsection{Effect of the Throat Length on the Internal Flow Field of the Nozzle}

In the case of a cavity diameter of $2 \mathrm{~mm}$ and a grooving degree of $30^{\circ}$, the nozzle model was simulated on three conditions of $2.5 \mathrm{~mm}, 3.0 \mathrm{~mm}$, and $4.0 \mathrm{~mm}$ nozzle throat lengths, as listed in Table 1 . As the simulation result, the pressure and velocity contour plots of the internal flow field for the nozzles with three different throat lengths are separately shown in Figure 5.

Figure 5(a), Figure 5(c), and Figure 5(e) are the pressure contour plots with nozzle throat length of $2.5 \mathrm{~mm}, 3.0 \mathrm{~mm}$, and $4.0 \mathrm{~mm}$, respectively. The results showed that the pressure inside the nozzle significantly changed when there were abrupt places on the in wall of nozzle throats. Moreover, from the inlet to the outlet, the pressure first increased to a certain value and then decreased. 
Table 1. Internal structural parameters of nozzles with different throat lengths.

\begin{tabular}{cccc}
\hline Nozzle No. & Cavity diameter $(\mathrm{mm})$ & Nozzle throat length $(\mathrm{mm})$ & Orifice grooving degree $\left({ }^{\circ}\right)$ \\
\hline 1 & 2 & 2.5 & 30 \\
2 & 2 & 3.0 & 30 \\
3 & 2 & 4.0 & 30 \\
\hline
\end{tabular}

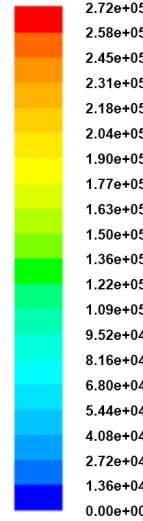

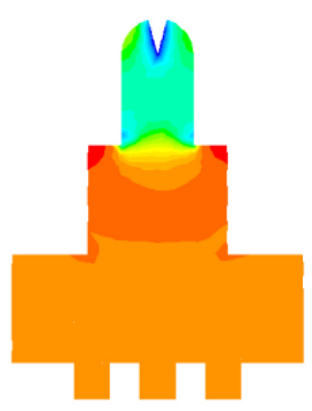

(a) Pressure, L = $2.5 \mathrm{~mm}$ (No.1)

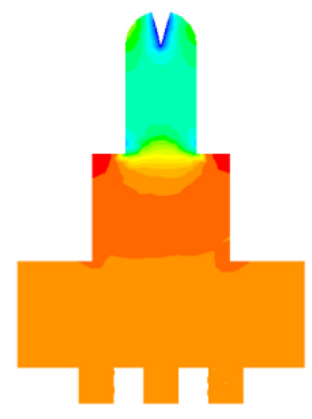

(c) Pressure, L = 3.0mm (No.2)

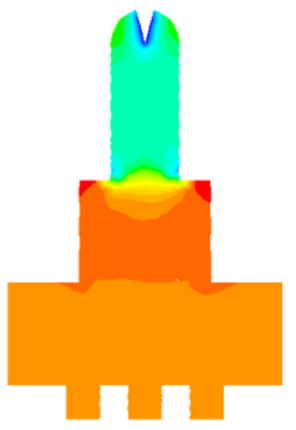

(e) Pressure, $L=4.0 \mathrm{~mm}(\mathrm{No} .3)$
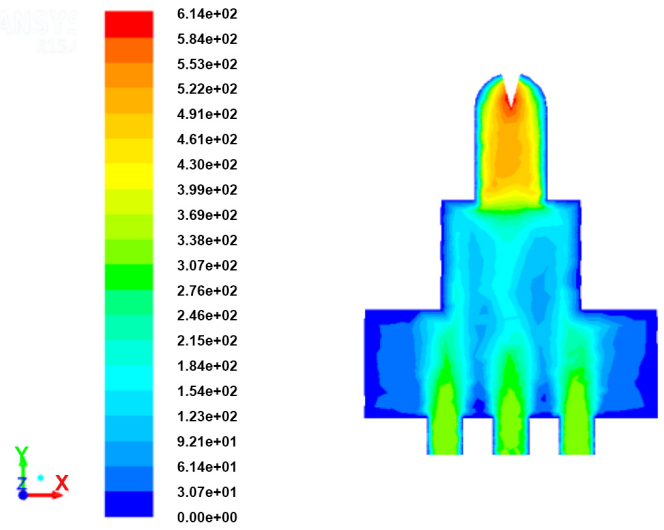

(b) Velocity, L = 2.5mm (No.1)
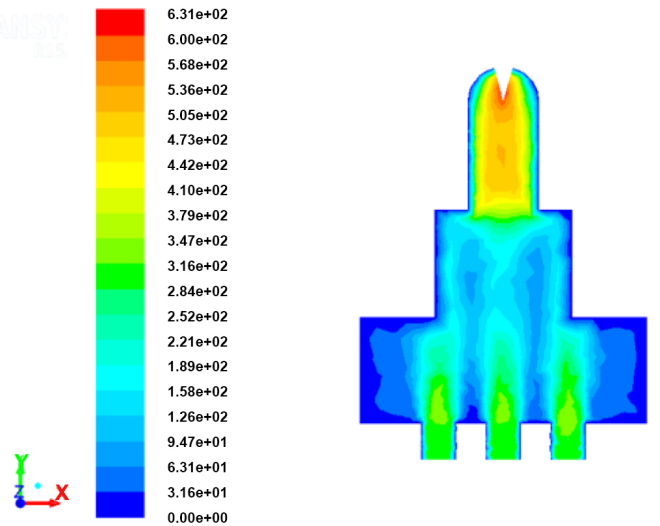

(d) Velocity, L $=3.0 \mathrm{~mm}$ (No.2)

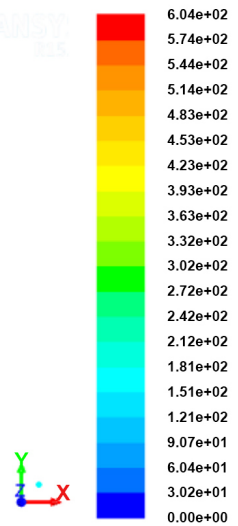

$74 \mathrm{e}+02$

$5.44 \mathrm{e}+02$

$4.83 e+02$

$3.63 \mathrm{e}+02$

$.02 e+02$

$12 \mathrm{e}+02$

$.07 \mathrm{e}+01$

$.02 e+01$

$0.00 e+00$

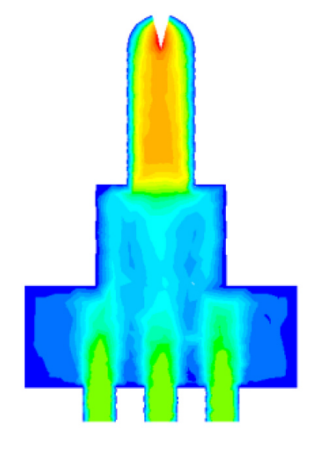

(f) Velocity, L = 4.0mm (No.3)

$1.35 \mathrm{e}+04$

Figure 5. The pressure and velocity contour plots for nozzle throat lengths of $2.5 \mathrm{~mm}, 3.0 \mathrm{~mm}$, and $4.0 \mathrm{~mm}$. 
With the increasing throat length, there is no significant change in the pressure of the internal flow field of the nozzle. Figure 5(b), Figure 5(d), and Figure 5(f) are the velocity contour plots at the nozzle length of $2.5 \mathrm{~mm}, 3.0 \mathrm{~mm}$, and 4.0 $\mathrm{mm}$. The flow velocity inside the nozzle significantly changed when there was an abrupt place for the internal cross section of the nozzle. Moreover, from the inlet to the outlet, the flow velocity first decreased and then increased. The velocity at the orifice portion was the largest.

Since the plots of the pressure and the velocity contours at each part of the flow field inside the nozzle exist in separate graphs, it is unable to make an intuitive and clear comparison. Therefore, the pressure and the velocity data on the center line of the internal flow field of the three nozzles were separately extracted in the FLUENT software and then respectively plotted in the same table for the purpose of conducting a comparative analysis and further contrasting with the conclusions obtained from the contour plots. The resulting plots were shown in Figure 6 and Figure 7. Figure 6 is the pressure profile on the center line of each nozzle with different nozzle throat lengths and Figure 7 is the velocity profile on the center line of each nozzle with different nozzle throat lengths.

It can be seen from Figure 6 that the pressure profiles on the center lines of Nozzle 1, 2, and 3 which had different throat lengths were almost the same, which indicated that the structural parameter of the nozzle throat length had similar effect on the pressure changing trend of the internal flow field of the nozzle. The internal flow field pressure significantly changed along the center of the nozzle throat for each of the three nozzles. Within a certain range, the flow field pressure first decreased and then increased from the inlet to the outlet of the nozzle.

It can be seen from Figure 6 that the velocity profiles on the center lines of Nozzle 1, 2, and 3 with different throat lengths were different, which showed that to some extent the velocity of the internal flow field of the nozzle was influenced by the structure parameter of the nozzle throat length and gradually decreased as the nozzle throat length increased. The more, the velocity profiles were relatively unchanged after the distance from the inlet surface was $3.0 \mathrm{~mm}$. for each one of the three nozzles, within a certain range the internal flow field velocity was gradually reduced from the inlet to the outlet of the nozzle.

\subsection{Effect of the Grooving Degree on the Internal Flow Field of the Nozzle}

As the case of a cavity diameter of $2 \mathrm{~mm}$ and a nozzle throat length of $3.5 \mathrm{~mm}$, three different nozzles with grooving degree of $15^{\circ}, 30^{\circ}$, and $45^{\circ}$ were shown in Table 2 . The simulated results of the pressure and velocity contour plots of internal flow field of the nozzles listed in Table 2 were shown in Figure 8.

It can be seen from the simulation results in Figure 8 that for the orifice grooving degrees of respectively $15^{\circ}, 30^{\circ}$, and $45^{\circ}$, the pressure and velocity inside the nozzle significantly changed when there were abrupt places for the in wall of nozzle throats. From the inlet to the outlet, the flow field pressure first 


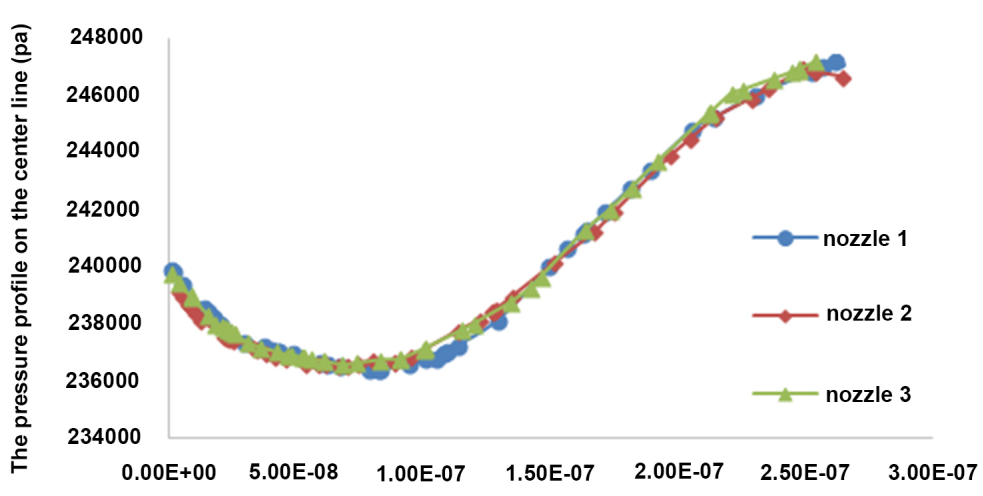

The distance from the points on the center line to the botton of the nozzle $\left(10^{7} \mathrm{~mm}\right)$

Figure 6. The pressure profile on the center line of each nozzle with different nozzle throat lengths.

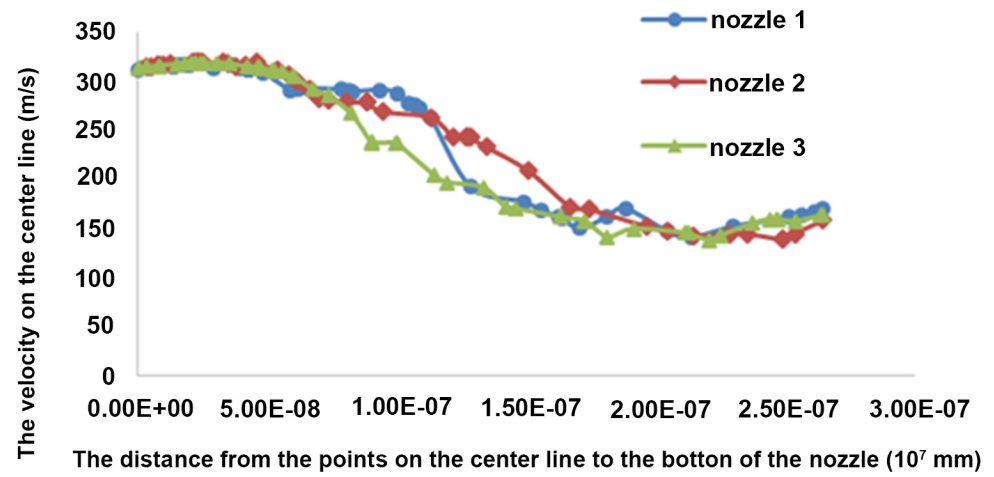

Figure 7 . The velocity profile on the center line of each nozzle with different nozzle throat lengths.

Table 2. Internal structural parameters of nozzles with different grooving degrees.

\begin{tabular}{cccc}
\hline Nozzle No. & Cavity diameter $(\mathrm{mm})$ & Nozzle throat length $(\mathrm{mm})$ & Orifice grooving degree $\left(^{\circ}\right)$ \\
\hline 4 & 2 & 3.5 & 15 \\
5 & 2 & 3.5 & 30 \\
6 & 2 & 3.5 & 45 \\
\hline
\end{tabular}

increased and then decreased. As the grooving degree increased, the internal flow field pressure of the nozzle gradually decreased. From the inlet to the outlet, the internal flow field velocity first decreased and then increased.

In order to compare the pressure and the velocity of the internal flow field of nozzles with different orifice grooving degrees, the data of the pressure and the velocity on the center line of nozzles with different grooving degrees were separately abstracted from the simulating results in FLUENT software and the profiles of the pressure and the velocity along the center lines of the nozzles were respectively plotted in the same diagram, as shown in Figure 9 and Figure 10. Figure 9 is the pressure profile on the center line of each nozzle with different orifice grooving degrees and Figure 10 is the velocity profile on the center line of each nozzle with different orifice grooving degrees. 


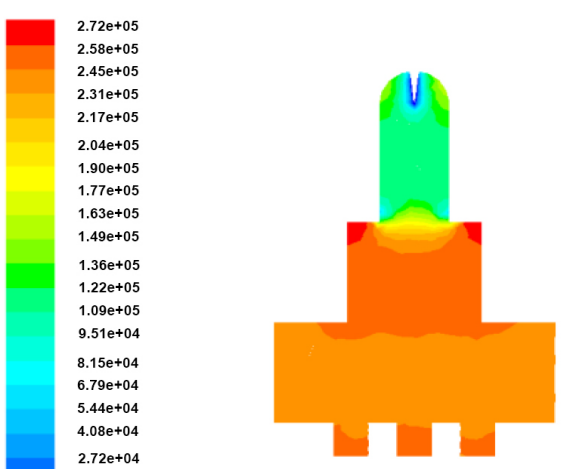

(a) Pressure, $\alpha=15^{\circ}$ (No.4)

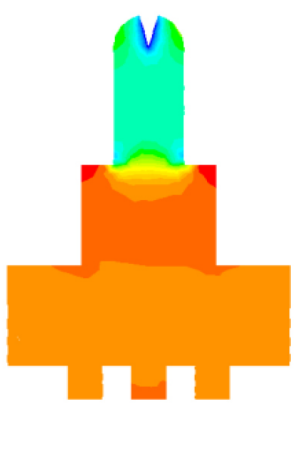

(c) Pressure, $\alpha=30^{\circ}$ (No.5)

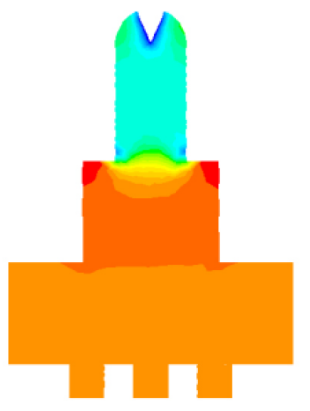

(e) Pressure, $\alpha=45^{\circ}$ (No.6)

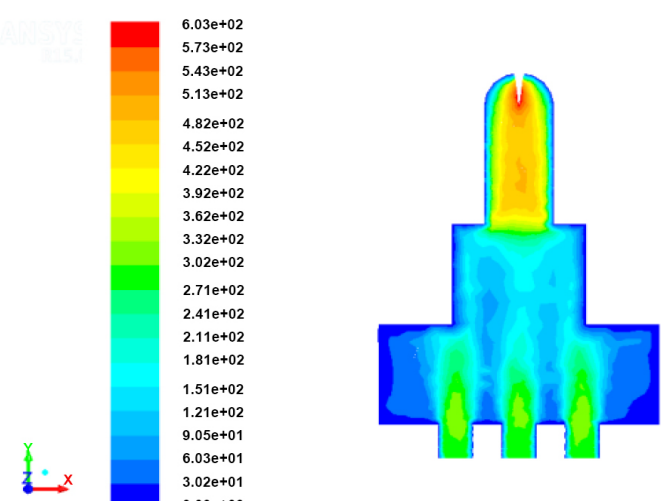

(b) Velocity, $\alpha=15^{\circ}$ (No.4)

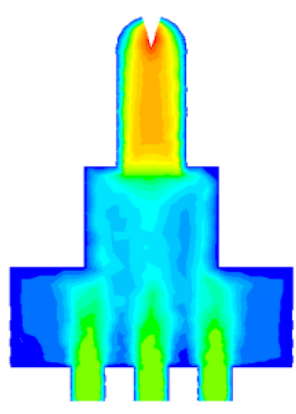

(d) Velocity, $\alpha=30^{\circ}$ (No.5)

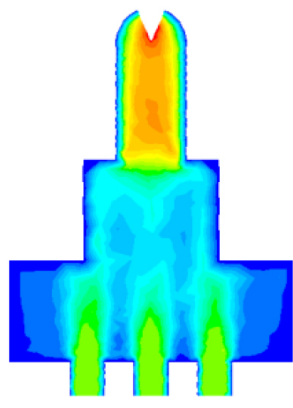

(f) Velocity, $\alpha=45^{\circ}$ (No.6)

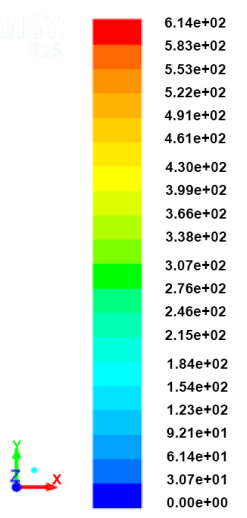

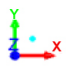

Figure 8. The pressure and velocity contour plots for orifice grooving degrees of $15^{\circ}, 30^{\circ}$, and $45^{\circ}$.

It can be seen from Figure 9 that the flow field pressure inside the nozzle was significantly influenced by the orifice grooving degree and gradually decreased with the increase of the orifice groove degree within a certain range. From the inlet to the outlet inside the same nozzle, after the pressure of the internal flow field gradually increased to a certain value, then begun to gradually decrease. 


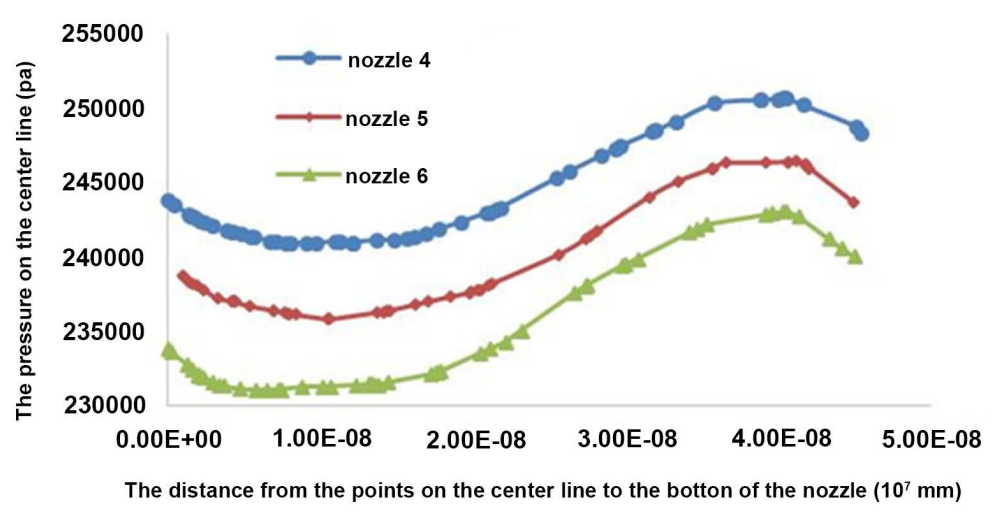

Figure 9. The pressure profile on the center line of each nozzle with different orifice grooving degrees.

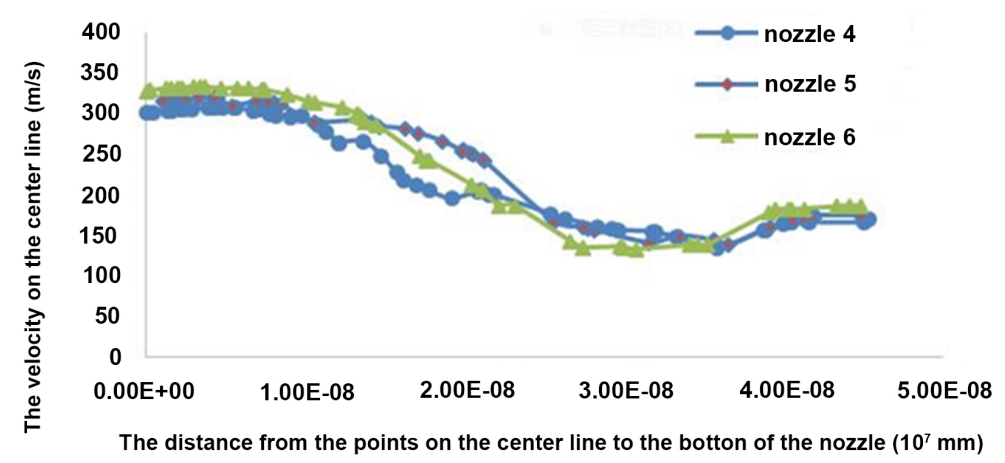

Figure 10. The velocity profile on the center line of each nozzle with different orifice grooving degrees.

It can be seen from Figure 10 that the velocity profiles on the center lines of Nozzle 4, 5, and 6 almost overlapped, which indicated that the orifice grooving degree had a negligible effect on the internal flow field velocity of the nozzle. For each velocity profile, namely for each nozzle with different orifice grooving degrees, the velocity of the internal flow field gradually decreased from the inlet to the outlet of the nozzle.

\section{Conclusion}

In consideration of the increasing velocity of the flow field, when the hydraulic pressure remains unchanged and the flow path becomes narrow, a re-designed nozzle with a multi-inlet and single-outlet step-like new structure was simulated for its internal flow field using ANSYS software. The results showed that the orifice grooving degree had a significant influence on the flow field pressure and velocity inside the nozzle, while the nozzle throat length had trivial effect on the internal flow field. The velocity of the inner flow field gradually increased and then decreased to a certain value, finally with a tendency of slightly increasing. From the results of simulation analysis, the optimal combination of the structure parameters of fan nozzle was that set Cavity diameter (D) as $2 \mathrm{~mm}$, orifice grooving degree as $30^{\circ}$, and the nozzle throat length (L) as $3 \mathrm{~mm}$. In addition, the 
pressure and the velocity of the inner flow field of the nozzle appeared significant change at the abrupt changing point of the internal structure of the nozzle in wall. This research just provided an alternative for trying to change the spray pressure and velocity in order to adapt to different kinds of agro-chemical application for different crops.

\section{Acknowledgements}

This research was financially supported by the National Key Research and Development Project of China (No.2017YFD0701004), the National Natural Science Foundation of China (31601228), the Youth Science Fund of the Beijing Natural Science Foundation (6164032). The authors acknowledge the National Experimental Station of Precision Agriculture of China.

\section{Conflicts of Interest}

The authors declare no conflicts of interest regarding the publication of this paper.

\section{References}

[1] Yang, X.-J., Yan, H.-R. and Zhou, H.-Y. (2005) Experimental Study on Fan Nozzle. Chinese Agricultural Mechanization, No. 1, 39-42.

[2] Meng, Y.-H., Zhou, G.-Q., Wu, C.-B., Wang, Z.-G. and Xu, X.-S. (2014) Discussion on Application and Extension of UAV Used for Agricultural Plant Protection in China. China Plant Protection, 34, 33-39.

[3] Torrent, X., Garcerá, C., Moltó, E., et al. (2017) Comparison between Standard and Drift Reducing Nozzles for Pesticide Application in Citrus: Part I. Effects on Wind Tunnel and Field Spray Drift. Crop Protection, 96, 130-143. https://doi.org/10.1016/j.cropro.2017.02.001

[4] Xing, Y.-Y., Han, J.-Y. and Liu, G.-C. (2013) The Analysis of the Prevention and Control of Garden Plant Diseases and Insect Pests. Heilongjiang Agricultural Sciences, No. 8, 51-54.

[5] Lu, Y. and Zhang, W.-D. (2003) Pesticide and Environmental Sustainable Development. Agricultural \& Technology, No. 1, 1-5.

[6] Lin, Z.-L., Guo, Y.-Q., Pu, Y., Mao, J.-S., Xia, K.-B., Yang, J. and Cheng, Z.-Q. (2011) Recent Advances in Research in Biological Control of Tobacco Diseases and Pests. Acta Tabacaria Sinica, 17, 90-94.

[7] Liu, P.-Z. (2007) Design of Distribution Bench for Precision Measuring Spray Nozzle Integrative Performance and on Fan Spray Nozzle. Nanjing Agricultural University, Nanjing.

[8] Dai, X.-F. (2003) Development Strategy of Plant Protection Science and Technology in China. Chinese Academy of Agricultural Sciences, Beijing.

[9] Zhai, Y. (2006) Study on Theory and Model of Chinese Ecological Agriculture. Northwest Agriculture \& Forestry University, Xianyang.

[10] Xu, Y.-L. (2009) Study on Mixers for Plant Protection Machinery and Chemical In-Line-Mixing Performances. Nanjing Forestry University, Nanjing.

[11] Ru, Y. (2009) Research on Aerial Pesticide Electrostatic Spraying System and Its Application. Nanjing Forestry University, Nanjing. 
[12] Wang, X. (2000) Study on Micrometerological Characterization and Herbicide Spray Application in Different Height Wheat Stubble Fields. China Agricultural University, Beijing.

[13] Zhang, M. (2016) Sector and Cone Sprayer with Air Assisted Device Performance Test Research. Shihezi University, Shihezi.

[14] Fan, X.-B., Deng, W. and Wu, G.F. (2016) Research Progress of Spray Drift Control Technology. Journal of Agricultural Mechanization Research, 38, 1-9.

[15] Zhang, J. (2015) Research on Mechanism of Enhancing Deposition and Synergistic Effect of the Spray Adjuvants on Pesticide. Gansu Agricultural University, Lanzhou.

[16] Shen, C.-J. (2014) Experimental Research and Numerical Simulation Effervescent Atomization Spray Nozzle. Shihezi University, Shihezi.

[17] Deng, W., He, X.K. and Ding, W.M. (2009) Experimental Study on Improving Deposition Rate Using PWM-Based Intermittent Spray from Enlarged Nozzle. Transactions of the CSAE, 25, 104-108. (In Chinese)

[18] Xie, C., He, X.-K., Song, J.-L., et al. (2013) Comparative Research of Two Kinds of Flat Fan Nozzle Atomization Process. Transactions of the Chinese Society of Agricultural Engineering, 29, 25-30. (In Chinese)

[19] Garcerá, C., Moltó, E. and Chueca, P. (2017) Spray Pesticide Applications in Mediterranean Citrus Orchards: Canopy Deposition and Off-Target Losses. Science of the Total Environment, 599-600, 1344. https://doi.org/10.1016/j.scitotenv.2017.05.029

[20] Bozdogan, A.M., Erdem, T. and Bozdogan, N.Y. (2017) Determination of Residue, Drift and Biological Efficacy of Different Spray Methods against Flower Thrips (Frankliniella spp.) (Thys. Thripidae) in Strawberries. AMA Agricultural Mechanization in Asia Africa \& Latin America, 48, 27-32.

[21] Salvador, R., Bautista-Capetillo, C., Burguete, J., et al. (2009) A Photographic Method for Drop Characterization in Agricultural Sprinklers. Irrigation Science, 27, 307-317. https://doi.org/10.1007/s00271-009-0147-2

[22] Miller, P.C.H., Ellis, M.C.B., Katan, J., et al. (2000) Effects of Formulation on Spray Nozzle Performance for Applications from Ground-Based Boom Sprayers. Crop Protection, 19, 609-615. https://doi.org/10.1016/S0261-2194(00)00080-6

[23] Burguete, J., Playan, E., Montero, J., et al. (2003) Improving Drop Size and Velocity Estimates of an Optical Disdrometer: Implications for Sprinkler Irrigation Simulation. Transaction of the $A S A B E, 50,2103-2116$. https://doi.org/10.13031/2013.24112

[24] Liu, G., Zhang, X.H., Fan, G.Q., Duan, J.B., Chu, X.Q., Zhou, G.P., Chen, X. and Wang, Y. (2014) Application Status and Development Trend of Cotton Spraying Machine. Journal of Agricultural Mechanization Research, 36, 225-228.

[25] Hu, B. (2008) Study on the Properties of Corona Plasma Discharge Atomization and Design of Sprayer Heads. Chang'an University, Chang'an.

[26] Luo, Y. (2008) Numerical Simulation of Interior Flow-Field about Plant Protection Nozzle. Hunan Agricultural University, Changsha.

[27] Cui, J. (2014) Mechanisms of Multi-Directional Breakup and Atomization of Liquid Jets and Performance Analysis. Hebei Agricultural University, Baoding.

[28] Fan, R. (2014) The Establishment of Spectrum and the Development of Application Software of Nozzle for Plant Protection. Northwest Agriculture \& Forestry University, Xianyang.

[29] Shen, C.-J., Tang, Z.-H., Meng, X.-J., Jia, S.-X., Zhou, Y. and Zheng, X. (2011) The 
Material Abrasion Properties and Anti-Attrition Methods of Plant Protection Nozzles. Journal of Agricultural Mechanization Research, 33, 21-24.

[30] Chen, Y.-J. (2009) Parametric Design and Experimental Investigations of Fan Nozzle Based on RP. Nanjing Agricultural University, Nanjing.

[31] Zhang, Q., Yuan, S.Q., Liu, J.P., et al. (2016) Optimization Design of Nozzle and Numerical Simulation of Internal Flow Field in Low-Pressure Sprinkler. Journal of Drainage and Irrigation Machinery Engineering, 34, 449-454. (In Chinese)

[32] Yuan, S.Q., Zhu, X.Y., Li, H. and Ren, Z.Y. (2005) Numerical Simulation of Inner Flow for Complete Fluidic Sprinkler Using Computational Fluid Dynamics. Transactions of the Chinese Society for Agricultural Machinery, 36, 46-49.

[33] Ding, X.H. (2018) The Design of the Multi-Channel Combined Nozzle of the Air-Borne Variable Sprayer and Study on the Performance. Nanjing Forestry University, Nanjing.

[34] Huang, F.G. (2014) Parametric Design of Plant Protection Nozzle. Northwest Agriculture \& Forestry University, Xianyang.

[35] Zhang, J.-W., Liu, S.-Y., Feng, Y., Zhang, X.-L. and Wang, N.-C. (2017) Numerical Simulation of Radial Flow Field in Multi-Nozzle Impinging Stream Reactor. Journal of Shenyang University of Chemical Technology, 31, 50-55+90.

[36] Sun, Y., Liu, X.J., Zhang, H.Y., Liu, F.J., Zhang, Q.Q. and Jin, B. (2013) Development of Gas-Solid Two-Phase Flow-Reaction CFD Model for Vortex Reactor. Transactions of the Chinese Society for Agricultural Machinery, 44, 194-200.

[37] Zhang, S.J., Li, X.H., Zhu, B.L. and Hu, Q.B. (2009) Applicability of $k-\varepsilon$ Eddy Viscosity Turbulence Models on Numerical Simulation of Centrifugal Pump. Chinese Journal of Mechanical Engineering, 45, 238-242. https://doi.org/10.3901/JME.2009.04.238

[38] Huang, Y. (2005) Numerical Simulation of Flow-Field around the Building Based on Fluent. Huazhong University of Science and Technology, Wuhan. 